\title{
Remote simulator training of coronary artery bypass grafting during the coronavirus disease 2019 pandemic
}

Kenichiro Takahashi, MD, ${ }^{\mathrm{a}}$ Chiharu Tanaka, MD, PhD, ${ }^{\mathrm{b}}$ Ryosuke Numaguchi, MD, PhD, ${ }^{\mathrm{c}}$ Yoshinori Kuroda, MD, PhD, ${ }^{\mathrm{d}}$ Hiroko Nemoto, MD, ${ }^{\mathrm{e}}$ Kunihiko Yoshino, MD, ${ }^{\mathrm{f}}$ Mika Noda, MD, PhD, ${ }^{\mathrm{g}}$ Yoshinori Inoue, $\mathrm{MD},{ }^{\mathrm{h}}$ and Kumiko Wada, MD, ${ }^{\mathrm{i}}$ the Committee of The Japanese Society for Cardiovascular Surgery Under Forty

\section{ABSTRACT}

Objectives: The coronavirus disease 2019 pandemic presents in-person exposure risk during surgical education. We aimed to validate the feasibility of fully remote faculty-supervised surgical training sessions focused on coronary artery bypass grafting using a synthetic simulator and online videochat software.

Methods: This observational study organized 24 sessions of 2-hour remote training Each session involved 3 trainees, 1 faculty member, and 1 host. A total of 70 trainees and 24 faculty members were enrolled. The participants joined the remote sessions via online videochat and performed focused training in coronary artery anastomosis using a commercially available simulator. A survey was conducted to validate the feasibility of the remote sessions. Performance improvement of the trainees who repeatedly participated $(n=13)$ were analyzed comparing initial and final scores of various performance indicators.

Results: All trainees and faculty members were satisfied with the efficacy of the remote session. Additionally, most trainees (79\%) and faculty members (95\%) agreed that the remote training sessions were equivalent to conventional onsite training seminars. A significant improvement between initial and last sessions was observed in the scoring components of near side (3.4 \pm 1.0 vs $4.1 \pm 0.9$; $P=.02)$, far side (3.3 \pm 0.8 vs $3.9 \pm 0.8 ; P=.03)$, external appearance (3.5 \pm 0.8 vs $4.2 \pm 0.7 ; P=.01$ ), and internal appearance ( $2.8 \pm 0.9$ vs $4.0 \pm 0.9 ;$ $P=.004)$.

Conclusions: Faculty-supervised remote surgical training sessions were executed with satisfactory results. This methodology may have important implications for surgical education during the coronavirus disease 2019 pandemic. (JTCVS Open 2021;8:524-33)

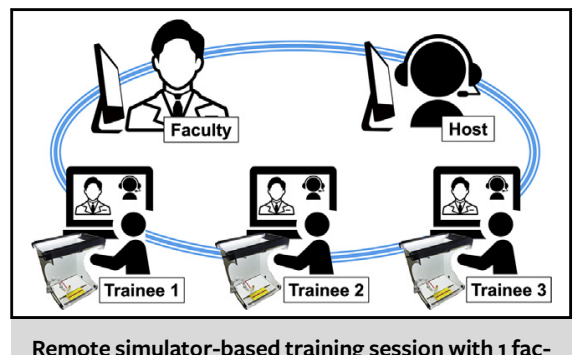

Remote simulator-based training session with $1 \mathrm{fac}-$ ulty member, 1 host, and 3 trainees.

\section{CENTRAL MESSAGE}

Our novel remote simulator-

based training could offer

faculty-supervised skill acquisi-

tion with satisfactory results and may be useful to maintain surgical education during the COVID-

19 pandemic.

\section{PERSPECTIVE}

We developed a novel methodology for remote faculty-supervised surgical training sessions in coronary anastomosis using synthetic simulators and online videochat service. The results suggested that our remote sessions were equivalent to conventional onsite training. This method may help surgical trainees to maintain their skill acquisition without in-person exposure during the COVID-19 pandemic.

See Commentaries on pages 534 and 536.

\footnotetext{
From the a Department of Cardiovascular Surgery, Nippon Medical School, Tokyo, Japan; ' Department of Cardiovascular Surgery, Tokai University Hachioji Hospital, Tokyo, Japan; ' Department of Cardiovascular Surgery, National Obihiro Hospital, Obihiro, Japan; ${ }^{\mathrm{d}}$ Department of Surgery II, Yamagata University Faculty of Medicine, Yamagata, Japan; ${ }^{\mathrm{e} D e p a r t m e n t ~ o f ~ C a r d i o v a s c u l a r ~ S u r g e r y, ~ Y o k o h a m a ~}$ City University Hospital, Yokohama, Japan; ${ }^{\mathrm{f}}$ Department of Cardiovascular Sur-

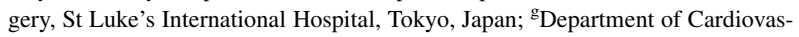
cular Surgery, Fujita Health University, Aichi, Japan; ${ }^{\mathrm{h}}$ Department of Cardiovascular Surgery, National Hospital Organization Okayama Medical Center, Okayama, Japan; and i Department of Cardiovascular Surgery, St Mary's Hospital, Kurume, Japan.
}

Supported by the Japanese Society for Cardiovascular Surgery.

Received for publication March 6, 2021; accepted for publication Aug 16, 2021; available ahead of print Sept 6, 2021.

Address for reprints: Kenichiro Takahashi, MD, Department of Cardiovascular Surgery, Nippon Medical School, 1-1-5 Sendagi, Bunkyo-ku, Tokyo 113-8603, Japan (E-mail: takahashi-ken@nms.ac.jp).

2666-2736

Copyright (C) 2021 The Author(s). Published by Elsevier Inc. on behalf of The American Association for Thoracic Surgery. This is an open access article under the CC BY-NC-ND license (http://creativecommons.org/licenses/by-nc-nd/4.0/).

https://doi.org/10.1016/j.xjon.2021.08.019 


\section{Abbreviations and Acronyms \\ $\mathrm{CABG}=$ coronary artery bypass grafting \\ COVID-19 = coronavirus disease 2019 \\ JSCVS $=$ The Japanese Society for \\ Cardiovascular Surgery \\ U-40= Committee of the Japanese Society for \\ Cardiovascular Surgery Under Forty \\ OFFJT = off-the-job training}

Video clip is available online.

During recent years, there has been a shift from traditional Halstedian methods toward more simulation-based education for developing the surgical skills of trainees. ${ }^{1}$ Young cardiac surgeons have less opportunities to operate on real patients in the current clinical environment because of the ethical concerns and more complex procedures performed on higher-risk patients. ${ }^{2-4}$ Trainees are therefore largely trained in the laboratory with simulation-based education and allowed to participate in graduated performance of procedures on patients. ${ }^{3}$ Considering the sentiment on this issue, the Japanese Board of Cardiovascular Surgery has started to obligate off-the-job training (OFFJT) for board certification, besides a board examination and inspection of surgical experience, since 2017. ${ }^{5}$ They defined OFFJT as faculty-supervised surgical skill acquisition using simulators (eg, synthetic vessel simulators, explanted porcine heart, and animal surgical laboratory), as opposed to patients. In response to this, the Japanese Society for Cardiovascular Surgery (JSCVS) Under-Forty (U-40), which is an official committee consisting of Japanese cardiovascular surgeons younger than age 40 years, has recently engaged in holding nationwide simulation-based surgical training seminars every few years. ${ }^{6}$ A total of more than 300 cardiovascular trainees have participated in the JSCVS U-40 seminars each year, whereas more than 100 faculty surgeons have participated as instructors.

The coronavirus disease 2019 (COVID-19) pandemic has changed our daily lives regarding physical distancing. Given all of these sudden changes, surgical trainees saw a dramatic drop in their in-person exposure to all aspects of their education, with no clear end point. This presents an extreme challenge for surgical educators and there have not yet been nationwide recommendations. ${ }^{7}$ JSCVS U-40 was forced to cancel all conventional onsite seminars and to reconsider every facet of surgical skill training during the COVID-19 pandemic.
JSCVS U-40 developed a novel remote training method for coronary artery bypass grafting $(\mathrm{CABG})$ using the synthetic coronary vessel simulator YOUCAN (EBM Corporation, Tokyo, Japan), and the online video-chat software Zoom (Zoom Video Communications, Inc, Calif). This study evaluated the feasibility of faculty-supervised focused training in coronary artery anastomosis in a completely isolated environment with no risk of close contact and viral infection.

\section{MATERIALS AND METHODS \\ Study Design}

This observational study was designed to validate the feasibility of fully remote faculty-supervised surgical training sessions in coronary artery anastomosis using YOUCAN and Zoom. This study also examined the utility of our novel remote surgical training method using a participant questionnaire and trainee skill evaluation. Nippon Medical School Institutional Review Board approved this observational study (A-2020045) on May 10, 2021. All participants agreed to the research and publication of this study with written consents.

\section{Participant Recruitment}

From September to December 2020, the JSCVS U-40 committee held 24 remote simulation-based surgical skill training sessions focused on coronary artery anastomosis. Each training session was held via Zoom from 5 PM to 7 PM on Saturday or Sunday, which is a suitable time frame for OFFJT for cardiovascular surgeons in Japan. To achieve high-quality remote training session directly supervised by a dedicated faculty surgeon with individual feedback, the number of trainees was limited to 3 per session (Figure 1).

Trainees younger than age 40 years who were dedicated or would be dedicated to cardiovascular surgery in Japan were recruited via the JSCVS U-40 website. They were required to enter the necessary information (eg, full name, institution, address, telephone number, e-mail address, postgraduate years, JSCVS membership identification number, and preferred date to participate) into the application form to join the remote training session. Google Forms (Google LLC, Mountain View, Calif) was used for the online application. Trainees were welcomed for either single or multiple participation at their own will. Faculties were recruited from attending surgeons who belong to leading institutions all over Japan. No reward was provided for the faculty members' participation.

\section{Instruments for the Remote Session}

A week before the predetermined date of the session, participants received the following instruments shipped to their home; YOUCAN, Anasthon A-1 Kit, a Castroviejo needle holder, micro forceps, coronary scissors, 7-0 monofilament polypropylene sutures (Prolene, Ethicon Inc; Johnson \& Johnson, Franklin Lakes, NJ), and a disposable vessel knife (Figure 2, A). YOUCAN is a commercially available high-fidelity silicone vascular model reproducing the fragile multilayered structure of native coronary artery and internal thoracic artery grafts. The inner diameter of vessel models is $2 \mathrm{~mm}$. Anasthon A-1 Kit is the plastic foldable base of the YOUCAN with a lighting system. This kit was developed for daily practice and remote training sessions using YOUCAN and intended to not only to fix the YOUCAN on its base (Figure 2, B) but also record participants' anastomoses with smartphones placed on the clear roof (Figure 2, $C$ ). After completion of the sessions, all instruments were sent back by the participants.

\section{Training Protocol}

In the current protocol, trainees experienced 2 components of simulation-based training in coronary artery anastomosis; prior free practice and real-time demonstration. Before the remote session, trainees 


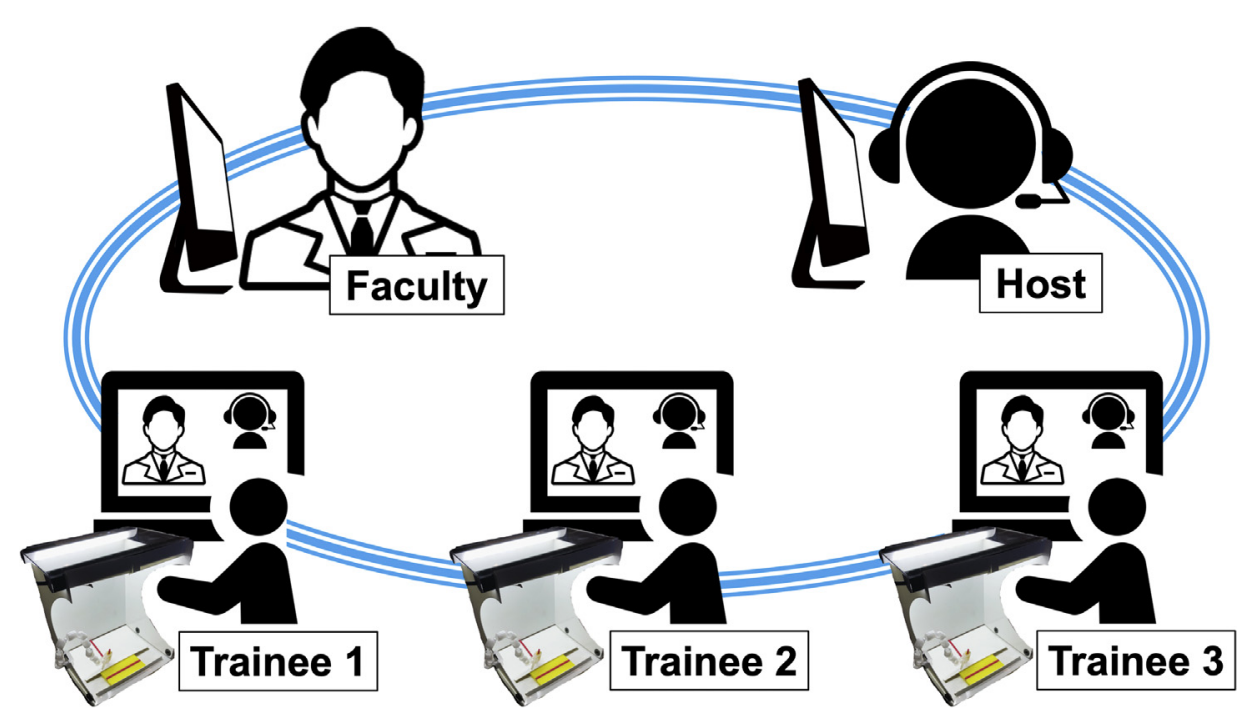

FIGURE 1. Participants in the remote simulator-based training session. This small-group teaching session involved 3 trainees, 1 faculty member, and 1 host via online videochat software. Trainees performed coronary anastomosis using a synthetic simulator and faculty members gave a formative feedback. This 2-hour remote training session was held 24 times, involving a cumulative total of 70 trainees and 24 faculty members in this study.

were required to perform free practice of simulation-based coronary artery anastomosis using YOUCAN and the Anasthon A-1 Kit. They had to perform at least 4 anastomoses and record all by taking videos with their own smartphones. They selected the best anastomosis video and sent it to an administrator in advance of the session. Video 1 shows a demonstration of anastomosing YOUCAN in the same setting of the current remote training. A smartphone captures the anastomosis from the clear roof of an Anasthon A-1 Kit.

At a prescribed time for the remote training session, 3 trainees, 1 faculty member, and 1 host (a volunteer from JSCVS U- 40 committee) logged in to the preinformed Zoom meeting (Figure 1). After the trainees and faculty logged into the session on both their personal computer and smartphone, the following programs proceeded, facilitated by the host:

- Presentation of prerecorded practice videos and faculty review (1020 minutes for each trainee),

- Key instruction from the faculty (10-15 minutes),

- Real-time demonstration by the trainees (10-20 minutes for each trainee),

- Individual feedback from the faculty using performance rating scores (5 minutes for each trainee), and

- Closing remarks.

\section{Performance Rating Scores}

Each trainee was directly supervised by a faculty surgeon during the real-time demonstration. After the demonstration, a faculty surgeon rated each trainee's performance according to a 5-point scoring scale (Table 1), modified from the Objective Structured Assessment of Technical Skills. ${ }^{2,4,8,9}$ This performance rating system was designed to notify trainees of their weaknesses and ways to improve their techniques at the end of the session. Given the formative feedback with rating scores, trainees were encouraged to perform further free practice to improve their techniques by themselves after the session. Performance improvement of the trainees who participated multiple times in these sessions were analyzed statistically comparing the scores between their initial and last session.

\section{Questionnaire Survey}

After the training session, the participants (trainees and faculties) were asked to complete a questionnaire consisting of 9 statements (Table 2), stating whether they agreed, neither agreed or disagreed, or disagreed. The purpose of the questionnaire was to assess the participants' impressions of our remote simulation-based training protocol. We also focused on educational equivalence of this remote training session compared with conventional on-site training seminars.

\section{Statistical Analysis}

First, we confirmed that the values of performance rating scores were normally distributed. Data were listed as mean \pm standard deviation. Paired $t$ test was used to compare the scores between the initial and last session. A $P$ value $<.05$ was considered statistically significant. All statistical analyses were performed with EZR (Saitama Medical Center, Jichi Medical University, Saitama, Japan), ${ }^{10}$ which is a graphical user interface for $\mathrm{R}$ (R Foundation for Statistical Computing, Vienna, Austria).

\section{RESULTS \\ Participant Characteristics}

Throughout the series of 24 remote training sessions, a cumulative total of 70 trainees participated from multiple institutions all over Japan. The number of individual trainees was 36. Among these 36 trainees, $13(36 \%)$ trainees participated multiple times; $1(3 \%)$ trainee participated 18 times, $4(11 \%)$ trainees participated 3 times, and 8 $(22 \%)$ trainees participated 2 times. The postgraduation duration of these 36 trainees ranged from 0 to 14 years with an average of 4.4 years.

\section{Achievement of the Remote Training Session}

All participants (trainees, faculty members, and hosts) successfully joined the sessions via Zoom as long as their own network environment worked normally. Figure 3 illustrates example images from Zoom screenshots during the sessions. Magnified images of the participants' anastomoses were vividly clear so that the faculties could evaluate trainees' performances in detail. 

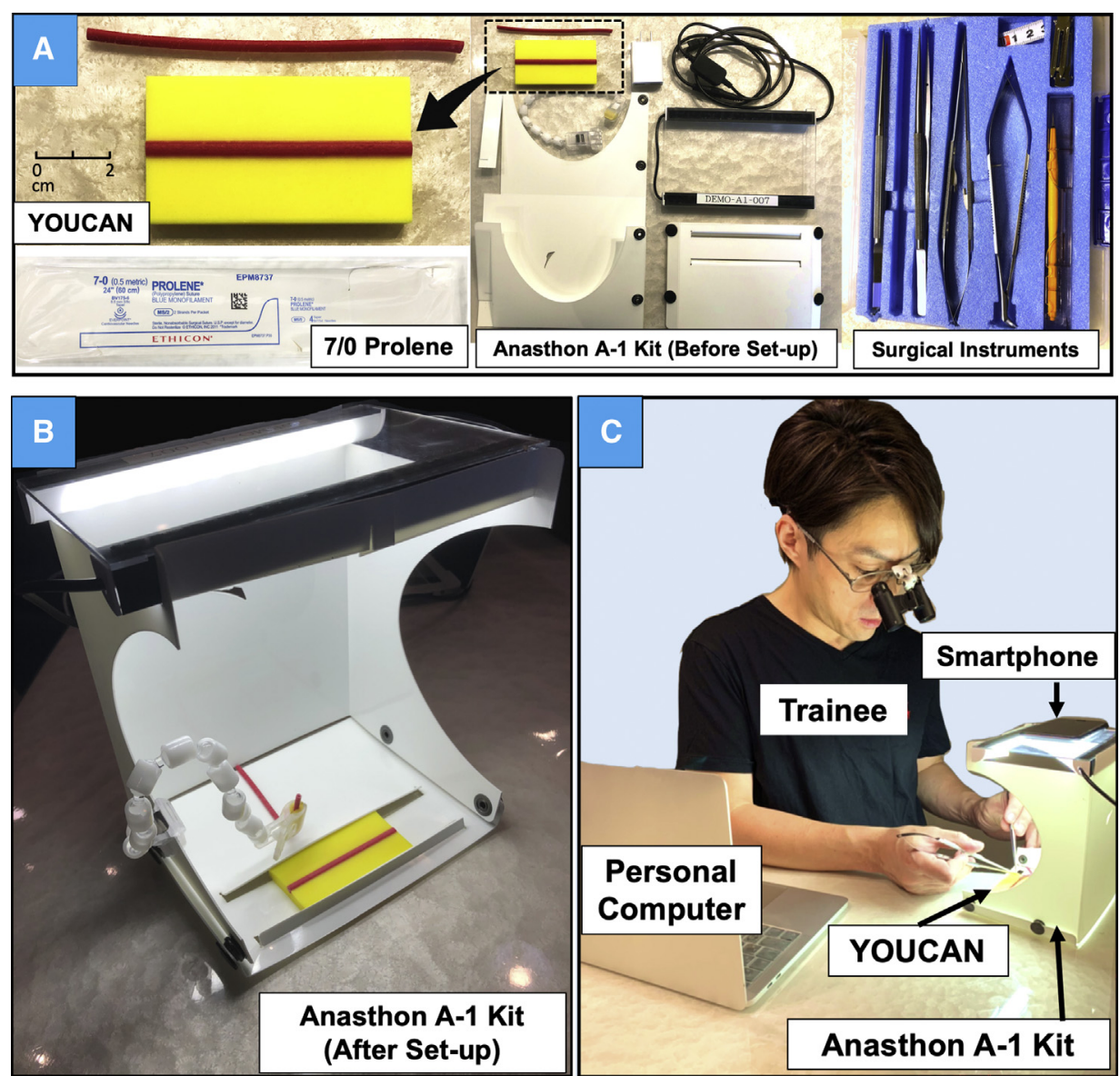

FIGURE 2. A, The instruments for the remote session. Participants received these instruments shipped to their home. YOUCAN (EBM Corporation, Tokyo, Japan) is a commercially available high-fidelity silicone vascular model imitating a coronary artery and an internal thoracic artery graft. Anasthon A-1 Kit (EBM Corporation) is a plastic-made foldable base of YOUCAN with a lighting system. Prolene (Ethicon Inc; Johnson \& Johnson, Franklin Lakes, NJ) is a monofilament nonabsorbable polypropylene suture. B, Completed form of Anasthon A-1 Kit in which YOUCAN is situated. Anasthon A-1 Kit was intended to use for not only fixation of YOUCAN on its base but also recording participants' anastomoses with smartphones placed on the clear roof. $\mathrm{C}$, Setting of a trainee participating in the remote session. Trainees need to log in to the session on both their own personal computer and smartphone because they need to watch the anastomosis of others closely on the personal computer screen while their smartphone captures their anastomosis.

Nearly all trainees (69 out of 70 [99\%]) had properly performed prior free practice and sent their video of anastomosis in advance of the sessions. Presentation of the prerecorded practice and faculty review were successfully performed in all sessions for these 69 trainees. Average time of the prerecorded practice video was $13.9 \pm 4.3$ minutes per 1 anastomosis.

The key instruction was entrusted to each faculty member, thus the manner of key instruction varied. More than half the faculty members presented key instructions orally (14 out of 24 [58\%]), whereas 4 faculties (17\%) gave slide presentations, and 6 faculties ( $25 \%$ ) performed demonstrations of anastomosis.

During the real-time demonstration by trainees, nearly all trainees (68 out of 70 [97\%]) successfully completed their anastomoses and received formative feedback from their faculty. One trainee $(1 \%)$ could not capture proper magnified images with his smartphone in Zoom, thus the faculty member could not give detailed feedback. One trainee $(1 \%)$ could not complete anastomoses due to a technical error.

\section{Trainees' Improvement on Performance Rating Scores}

The performance rating score comparison between the initial and last session is summarized in Table 3 and Figure 4. A significant improvement was observed in the components of anastomosing skill of near side portion $(3.4 \pm 1.0$ vs $4.1 \pm 0.9 ; P=.02)$, far side portion $(3.3 \pm 0.8$ vs $3.9 \pm 0.8 ; P=.03)$, external appearance of anastomosis ( $3.5 \pm 0.8$ vs $4.2 \pm 0.7 ; P=.01)$, and internal appearance of anastomosis $(2.8 \pm 0.9$ vs $4.0 \pm 0.9$; $P=.004)$. A nonsignificant trend toward higher scores in the last session was observed in all the other components 


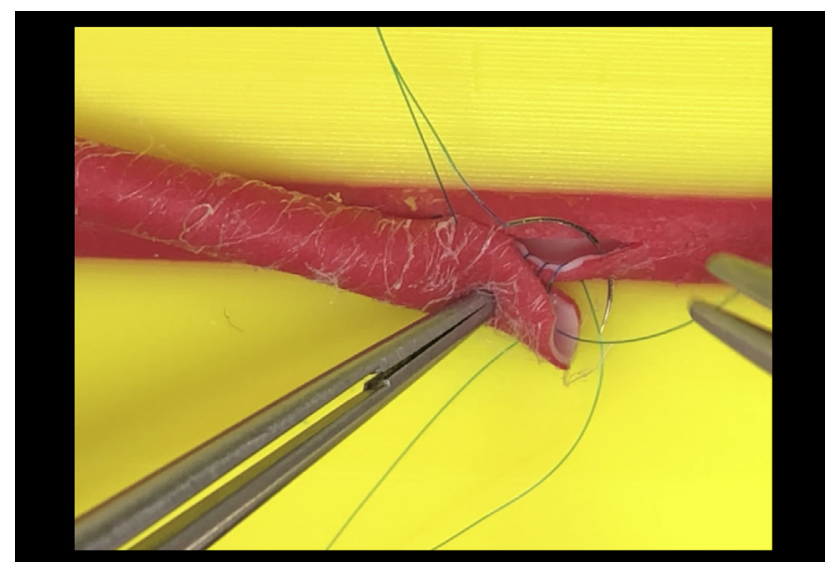

VIDEO 1. A demonstration of anastomosis using YOUCAN (EBM Corporation, Tokyo, Japan) and Anasthon A-1 Kit (EBM Corporation) in the same setting of the remote training. A smartphone captures the anastomosis of YOUCAN from the clear roof of an Anasthon A-1 Kit. Video available at: https://www.jtcvs.org/article/S2666-2736(21)00248-5/fulltext.

except anastomosing time $(3.4 \pm 0.9$ vs $3.2 \pm 1.0$; $P=.63)$.

\section{Questionnaire Survey}

Of the 36 trainees and 24 faculty members, $33(92 \%)$ trainees and $20(83 \%)$ faculty members completed the questionnaire survey. The results of questionnaire survey are summarized in Table 2. All (53 out of $53[100 \%]$ ) participants agreed that this remote training session was effective in improving surgical skill. Additionally, the vast majority (45 out of $53[85 \%]$ ) of participants, including trainees (26 out of $33[79 \%]$ ) and faculties (19 out of 20 [95\%]) reported that this remote training session was equivalent to conventional onsite training seminars. Several participants noted that this remote session was superior to conventional onsite seminars in that they could obtain more individual and detailed feedback using a smallgroup teaching method. Performing anastomoses with YOUCAN and Anasthon A-1 Kit was regarded as realistic enough for the majority of trainees (23 out of $33[70 \%]$ ) and faculty members (16 out of $20[80 \%]$ ), although the rest of participants mentioned that it felt somewhat difficult and uncomfortable anastomosing YOUCAN inside an Anasthon A-1 Kit. Several faculties (10 out of 20 [50\%]) argued that components of the performance rating scores were not appropriate; they mentioned that anastomosing time should be excluded because trainees should put a higher priority on quality, not time.

\section{DISCUSSION}

This study was a preliminary investigation to validate the methodology of remote surgical training sessions focused on CABG using a synthetic simulator. The results suggest that this newly developed training protocol was an effective
TABLE 1. Components of the performance rating scores

\begin{tabular}{|c|c|c|c|c|c|}
\hline \multirow[b]{2}{*}{ Evaluation points } & \multicolumn{5}{|c|}{ Score } \\
\hline & Excellent & Good & Average & Poor & Error \\
\hline $\begin{array}{l}\text { 1. Coronary artery } \\
\text { incision (straightness, } \\
\text { centering, length } \\
\text { appropriate) }\end{array}$ & 5 & 4 & 3 & 2 & 1 \\
\hline $\begin{array}{l}\text { 2. Anastomosing skill of } \\
\text { heel portion (bite/ } \\
\text { spacing appropriate, } \\
\text { needle/suture } \\
\text { management) }\end{array}$ & 5 & 4 & 3 & 2 & 1 \\
\hline $\begin{array}{l}\text { 3. Anastomosing skill of } \\
\text { near side portion (bite/ } \\
\text { spacing appropriate, } \\
\text { needle/suture } \\
\text { management) }\end{array}$ & 5 & 4 & 3 & 2 & 1 \\
\hline $\begin{array}{l}\text { 4. Anastomosing skill of } \\
\text { toe portion (bite/ } \\
\text { spacing appropriate, } \\
\text { needle/suture } \\
\text { management) }\end{array}$ & 5 & 4 & 3 & 2 & 1 \\
\hline $\begin{array}{l}\text { 5. Anastomosing skill of } \\
\text { far side portion (bite/ } \\
\text { spacing appropriate, } \\
\text { needle/suture } \\
\text { management) }\end{array}$ & 5 & 4 & 3 & 2 & 1 \\
\hline $\begin{array}{l}\text { 6. Overall instrument } \\
\text { handling technique (use } \\
\text { of forceps and needle } \\
\text { holder, needle transfer) }\end{array}$ & 5 & 4 & 3 & 2 & 1 \\
\hline $\begin{array}{l}\text { 7. Knot tying skill } \\
\text { (adequate tension, } \\
\text { finger, and hand follow } \\
\text { for knots) }\end{array}$ & 5 & 4 & 3 & 2 & 1 \\
\hline $\begin{array}{l}\text { 8. External appearance of } \\
\text { completed anastomosis } \\
\text { (shape affirmation, dog } \\
\text { ear deformity) }\end{array}$ & 5 & 4 & 3 & 2 & 1 \\
\hline $\begin{array}{l}\text { 9. Internal appearance of } \\
\text { completed anastomosis } \\
\text { (patency affirmation, } \\
\text { absence of stenosis) }\end{array}$ & 5 & 4 & 3 & 2 & 1 \\
\hline $\begin{array}{l}\text { 10. Anastomosing time }(5 \text { : } \\
\sim 8 \mathrm{~min}, 4: \sim 10 \mathrm{~min}, 3 \text { : } \\
\sim 13 \mathrm{~min}, 2: \sim 16 \mathrm{~min}, \\
1: \sim 16 \mathrm{~min})\end{array}$ & 5 & 4 & 3 & 2 & 1 \\
\hline
\end{tabular}

Scores: 5 = excellent, able to accomplish goal without hesitation, showing excellent flow; 4 = good, able to accomplish goal deliberately, with minimal hesitation, showing good flow; 3 = average, able to accomplish goal with hesitation, discontinuous flow; 2 = poor, able to partially accomplish goal with hesitation; and $1=$ error, unable to accomplish goal, marked hesitation. These are adapted from the Objective Structured Assessment of Technical Skill. ${ }^{2,4,8,9}$

method, judged equivalent to conventional onsite training programs by the recruited participants from all over Japan. The greatest achievement of this project was to substantiate 
TABLE 2. Questionnaire survey to the participants

\begin{tabular}{|c|c|c|c|}
\hline Statement & Agree & Neither & Disagree \\
\hline \multicolumn{4}{|l|}{ Questionnaire to the trainees (33 respondents) } \\
\hline Entering application form and receiving instruments were easy & $27(82)$ & $6(18)$ & 0 \\
\hline Participating in the session via Zoom* was smooth & $32(97)$ & $1(3)$ & 0 \\
\hline Performing an anastomosis with YOUCAN $\dagger$ and Anasthon A-1 Kit $\dagger$ was realistic & $23(70)$ & $10(30)$ & 0 \\
\hline Combination of prior free practice and real-time demonstration was beneficial & $31(94)$ & 0 & $2(6)$ \\
\hline The faculty's instruction was educational & $32(97)$ & $1(3)$ & 0 \\
\hline Performance rating scores were beneficial to understand feedback & $25(76)$ & $8(24)$ & 0 \\
\hline Time allocation during the session was appropriate & $28(85)$ & $1(3)$ & $4(12)$ \\
\hline This remote training session was equivalent to conventional onsite seminars & $26(79)$ & $2(6)$ & $5(15)$ \\
\hline This remote training session was effective to improve surgical skill & $33(100)$ & 0 & 0 \\
\hline \multicolumn{4}{|l|}{ Questionnaire to the faculties (20 respondents) } \\
\hline Entering application form and receiving instruments were easy & $17(85)$ & $3(15)$ & 0 \\
\hline Participating in the session via Zoom* was smooth & $17(85)$ & $3(15)$ & 0 \\
\hline Performing an anastomosis with YOUCAN $\dagger$ and Anasthon A-1 Kit $\dagger$ was realistic & $16(80)$ & $3(15)$ & $1(5)$ \\
\hline Combination of prior free practice and real-time demonstration was beneficial & $19(95)$ & 0 & $1(5)$ \\
\hline The host's operation was comprehensible during the session & $20(100)$ & 0 & 0 \\
\hline Components of performance rating scores were appropriate & $10(50)$ & $9(45)$ & $1(5)$ \\
\hline Time allocation during the session was appropriate & $18(90)$ & $2(10)$ & 0 \\
\hline This remote training session was equivalent to conventional on-site seminars & $19(95)$ & 0 & $1(5)$ \\
\hline This remote training session was effective to improve surgical skill & $20(100)$ & 0 & 0 \\
\hline
\end{tabular}

Values are presented as n (\%). *Zoom Video Communications Inc, San Jose, Calif. †EBM Corporation, Tokyo, Japan.

the feasibility of faculty-supervised surgical education in a completely isolated environment without in-person exposure.

There are several key factors contributing to this successful series of remote sessions. Firstly, YOUCAN was an optimal tool for the current remote training method. Since YOUCAN was introduced as a training tool for CABG in Japan, ${ }^{11}$ it has been refined repeatedly to more closely approximate the real texture of a coronary artery and an internal thoracic artery. Several studies were reported on anastomosis analysis and training efficacy using this reliable simulator. ${ }^{12,13}$ Although an explanted porcine heart was frequently featured in past literature on simulationbased training, ${ }^{2,14}$ its greatest disadvantages were restricted availability within the laboratory and animal welfare. ${ }^{15} \mathrm{On}$ the contrary, YOUCAN, which is a synthetic and deliverable vessel simulator, facilitated remote training safely at home. Secondly, development of Internet technology and spread of smartphones equipped with high-performance cameras were also key factors behind this achievement. Zoom, an online videochat service, provides highresolution video sufficient to observe detailed small vessel anastomosis (Figure 3). Several faculty members mentioned that a magnified view of an anastomosis on the Zoom screen was much clearer and easier to observe than an actual anastomosis site, which they had seen in the conventional onsite seminars. Therefore, Zoom was considered an ideal distance education tool even for surgical training sessions. Thirdly, the small-group (3 trainees, 1 faculty member, and 1 host) teaching system was suitable for these remote sessions. This setting enabled faculty to observe each trainee's anastomosis carefully 1 by 1 , and give feedback within the allotted time. To maximize the skill acquisition within the limited time frame, we required trainees to perform free practice before the session. This 2-step skill training was largely accepted as a beneficial method in the questionnaire survey (Table 2). Lastly, the host played an important and necessary role for smooth progress of remote sessions. The host had to manipulate the Zoom application to guide the session properly, and assist active discussion between the participants across the whole course. Accordingly, the hosts were elected from members of JSCVS U-40, and were well trained during several rehearsals. As a result, we could achieve the highly effective remote training sessions with $100 \%$ approval of the host's appropriate operation in the faculty members' questionnaire survey throughout the entire series of the sessions.

Educational experience with the training model may not be associated with improved technical skills if the exposure is not repeated. ${ }^{2,16}$ The current result also supports this theory: 13 trainees who repeatedly participated in the remote training sessions exhibited performance improvement in their final session. Statistically significant performance improvement was observed in the components of anastomosing skill of far- or near-side portion and external/internal appearance of the completed anastomoses, whereas most other components of the performance rating scores also showed a nonsignificant trend toward higher scores in the last session (Table 3 and Figure 4). The external/internal appearance of the anastomoses, which exhibited the most remarkable improvement, are considered to be the most important evaluation points because they are directly 


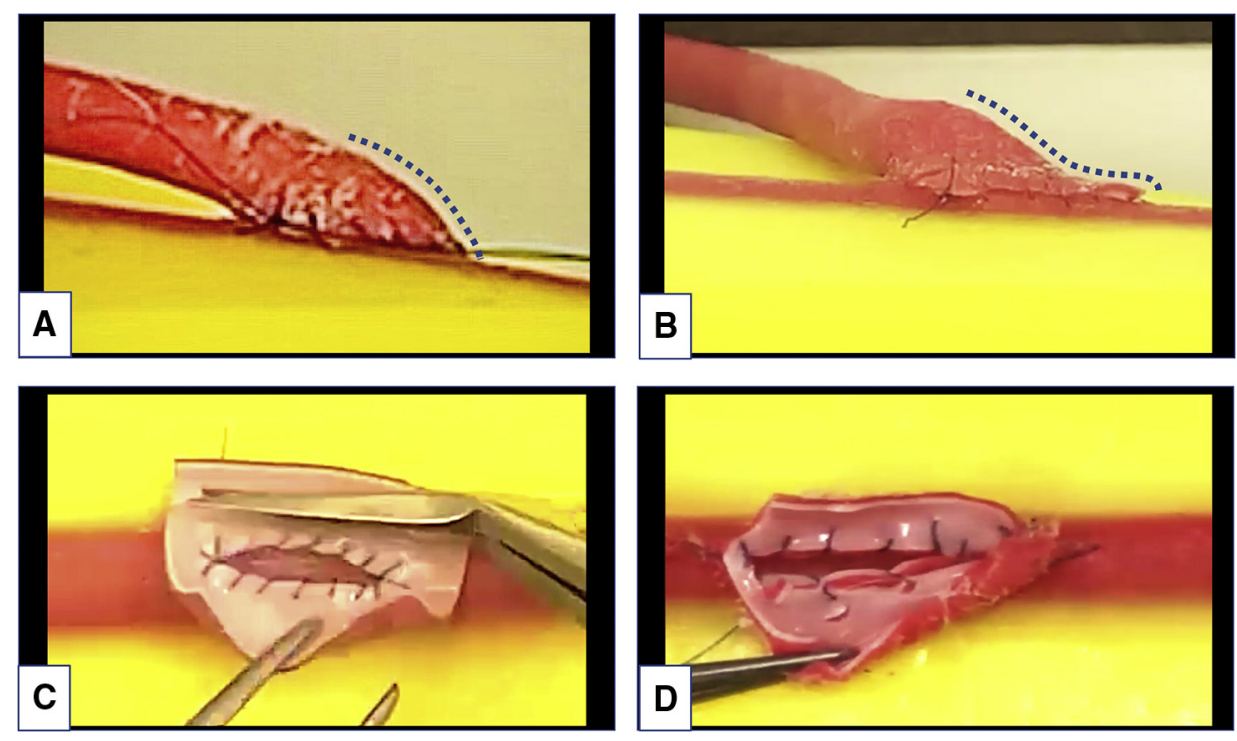

FIGURE 3. Four representative example images of the Zoom (Zoom Video Communications Inc, San Jose, Calif) screen displaying completed anastomoses during the remote session. Each anastomosis was performed by a different participant. A, High-scored anastomosis exhibits an ideal external shape with adequate bulge. B, Low-scored anastomosis exhibits an unfavorable external shape with hollow deformity. C, High-scored internal appearance shows appropriate bites and spacings without intimal damage. D, Low-scored internal appearance shows irregular bites and spacings with intimal injuries.

linked to graft patency. These components are tangible evaluation points reflecting comprehensive anastomosing skill; thus, achievement of improvement can be observed more directly relative to the other technical components. However, the current result is insufficient to determine whether our remote sessions offer substantial technical improvement, because the available data regarding performance rating

TABLE 3. Mean performance rating scores comparing the initial and last session among 13 trainees who participated repeatedly

\begin{tabular}{lccc}
\hline \multicolumn{1}{c}{ Evaluation points } & Initial score & Last score & $\boldsymbol{P}$ value \\
\hline 1. Coronary artery incision & $4.3 \pm 0.6$ & $4.5 \pm 0.7$ & .34 \\
$\begin{array}{l}\text { 2. Anastomosing skill of heel } \\
\text { portion }\end{array}$ & $3.7 \pm 0.8$ & $4.1 \pm 0.9$ & .23 \\
$\begin{array}{l}\text { 3. Anastomosing skill of near } \\
\text { side portion }\end{array}$ & $3.4 \pm 1.0$ & $4.1 \pm 0.9$ & .02 \\
\hline $\begin{array}{l}\text { 4. Anastomosing skill of toe } \\
\text { portion }\end{array}$ & $3.3 \pm 0.9$ & $3.5 \pm 1.0$ & .34 \\
$\begin{array}{l}\text { 5. Anastomosing skill of far } \\
\text { side portion }\end{array}$ & $3.3 \pm 0.8$ & $3.9 \pm 0.8$ & .03 \\
$\begin{array}{l}\text { 6. Overall instrument } \\
\text { handling technique }\end{array}$ & $4.0 \pm 0.8$ & $4.5 \pm 0.8$ & .44 \\
\hline $\begin{array}{l}\text { 7. Knot tying skill } \\
\text { 8. External appearance of } \\
\text { completed anastomosis }\end{array}$ & $3.5 \pm 0.8$ & $4.2 \pm 0.7$ & .01 \\
\hline 9. Internal appearance of \\
completed anastomosis
\end{tabular}

Values are presented as mean \pm standard deviation. Performance rating scores were compared for the initial session versus the last session using paired $t$ test. was limited to only $13(36 \%)$ trainees who participated repeatedly. Because the time and effort that recruited trainees from multiple institutions could spend on our preliminary remote training sessions was limited during the extraordinary circumstances presented by the COVID-19 pandemic, we welcomed single participation and did not dare organize the time-consuming curriculum to require multiple participations. A single 2-hour remote training itself may be insufficient to produce substantial performance improvement for every participant; thus, we did not conduct performance comparison between the baseline and the end of each session. We rather aimed to notify trainees of their technical weaknesses and ways to improve them within a single participation, providing intensive faculty supervision and individual performance assessment. We believed that these instructions would encourage trainees to sharpen their skill through further constant daily practice by themselves, after the session. As a result, there were 13 motivated trainees who participated repeatedly with improved performance compared to their initial participation. This result indicates that our remote session could successfully inspire some participants to achieve performance improvement.

Since December 2019, we have been in the midst of the worldwide COVID-19 pandemic, the defining global health crisis and the greatest challenge we have faced. Protecting the health, safety, and well-being of cardiovascular surgeons, and ultimately patients, is paramount, and serves as the reason for the decision to cancel all conventional academic meetings and surgical training seminars. Meanwhile, cardiovascular surgery training is demanding of time and commitment, and require clear end points. This 


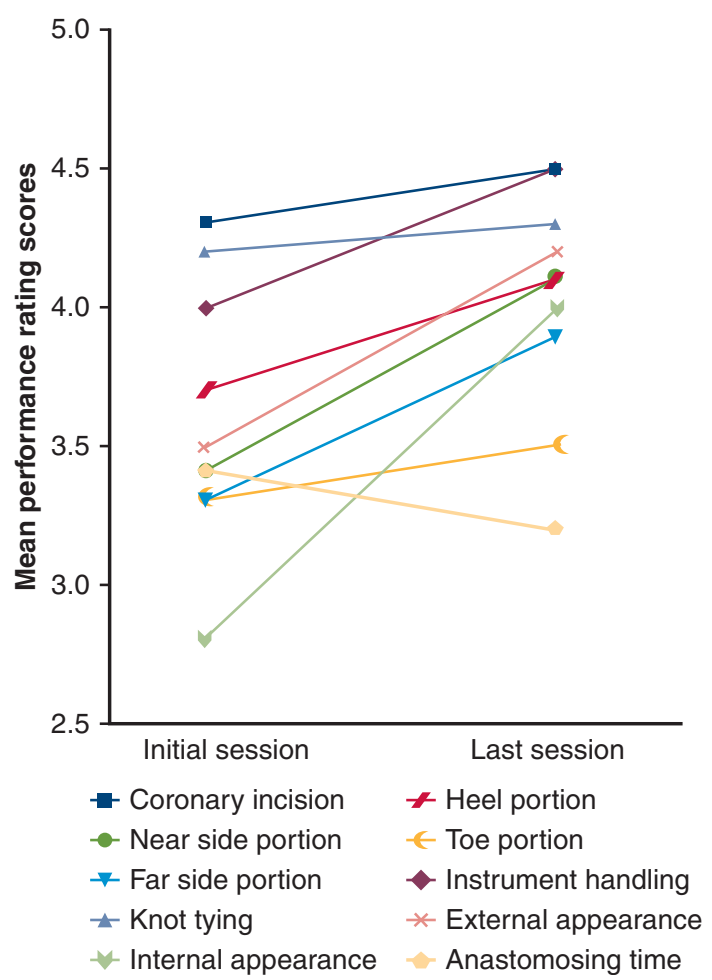

FIGURE 4. The performance rating score comparison between the initial and last session of the trainees who participated repeatedly $(n=13)$. Each line represents the mean score of each component of the 13 trainees' performance rating scores. A significant improvement was observed in the components of anastomosing skill of near side portion $(3.4 \pm 1.0 \mathrm{vs}$ $4.1 \pm 0.9 ; P=.02)$, far side portion (3.3 \pm 0.8 vs $3.9 \pm 0.8 ; P=.03)$, external appearance of anastomosis $(3.5 \pm 0.8$ vs $4.2 \pm 0.7 ; P=.01)$, and internal appearance of anastomosis $(2.8 \pm 0.9$ vs $4.0 \pm 0.9$; $P=.004)$, whereas most other components showed nonsignificant trend toward higher scores in the last session.

has led to more widespread use of virtual platforms in place of in-person interaction and other traditional educational methods. ${ }^{17,18}$ Accordingly, JSCVS U-40 searched for solutions to meet the urgent need of educating young surgeons and eventually launched this remote surgical training. Seeing the result of participants' questionnaire survey, our remote sessions gained a certain level of appreciation: the majority of the participants regarded our remote training as equivalent to conventional onsite surgical education. However, this result does not mean that the current virtual platform can always replace conventional onsite training. In past JSCVS U-40 on-site surgical training seminars, faculty members taught various procedures (eg, CABG, valve surgery, aortic surgery, and others) to many trainees using a combination of synthetic tissue simulation and real tissue simulation (ie, wet-laboratory exercises). On the other hand, our current training method is still restricted to individualized instruction of coronary anastomosis using a synthetic simulator. Although the combined use of YOUCAN and Anasthon A-1 Kit satisfied the majority of trainees (23 out of $33[70 \%]$ ) and faculties (16 out of 20 [80\%]) as a realistic simulator, synthetic simulators can never mimic the feel of living human tissue, the complexity of human physiology, or all the psychosocial nuances of real patient care. ${ }^{14,19}$ Further exploitation of real tissue simulators, which are safely available in the current virtual platform will be required. Additionally, there remains a challenge regarding administrative efficiency. Because online chat is suitable for small-group bidirectional discussion, our preliminary remote training adopted individualized instruction in a 3 to 1 trainee to faculty ratio, spending 2 hours per session for 24 sessions. This small-group-intensive method may be among the reasons why the current remote training was highly applauded by participants, whereas a much greater deal of labor was needed to administrate the whole course compared with the past onsite training seminars, which could involve far more trainees at once. Future work should therefore aim to establish more efficient administration of remote training programs.

\section{Limitations}

Among the study limitations is dispersion of postgraduation duration in this study population ranging from 0 to 14 years. Also, participation frequency varied between individuals. In the current series of remote training sessions, the above conditions were dependent on spontaneous application from participants all over Japan, thus not controllable. To obtain more useful data regarding performance evaluation, a larger uniform cohort needs to experience the same curricula.

Another limitation is lack of performance rating consistency and equality. Although the 5-point global rating scale adapted from the Objective Structured Assessment of Technical Skills is a widely used fundamental tool for performance assessment, the rated scores eventually depended on each faculty member's subjective judgment, thus were not completely consistent. In addition, the current remote sessions involved face-to-face meeting on the virtual platform in a nonblinded manner. Although every faculty surgeon intended to provide fair ratings to inform trainees of their weaknesses, there still remains the possibility that faculty surgeons had an unconscious bias to score the final sessions higher. To fairly correlate performance scores and remote training participation, performance should ideally be rated under identical conditions by the same faculty members in a blinded manner.

\section{CONCLUSIONS}

This study validated the novel methodology of facultysupervised remote surgical training session focused on coronary artery anastomosis. This newly developed training method achieved completely remote surgical skill acquisition with intensive faculty supervision using synthetic 
Remote Simulator Training of Coronary Artery Bypass Grafting during the COVID-19 Pandemic

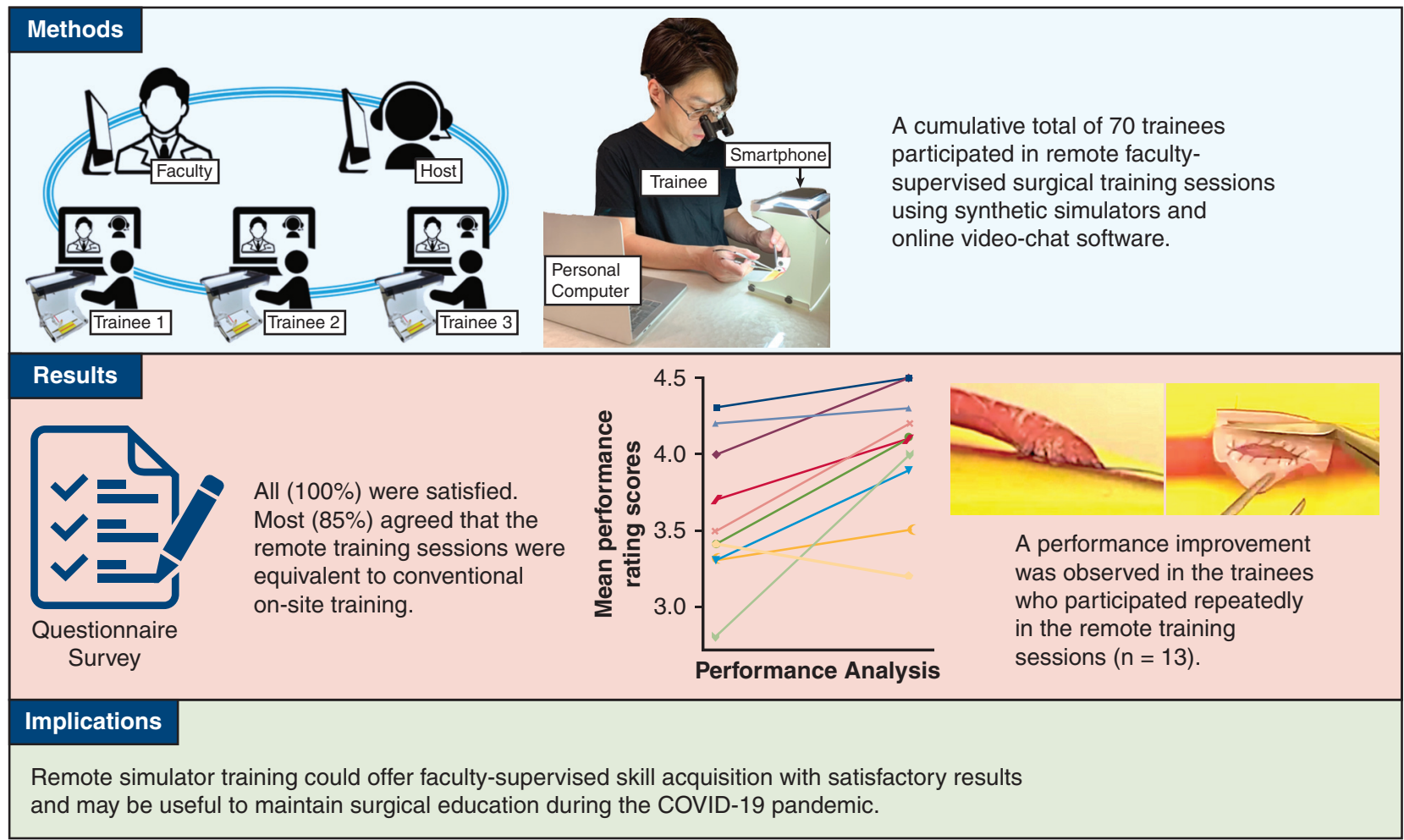

FIGURE 5. Graphical summary of the study demonstrating that our newly developed training method achieved completely remote faculty-supervised surgical skill acquisition using synthetic simulators and online videochat software. The results of this study have important implications on surgical education during the coronavirus disease 2019 (COVID-19) pandemic.

simulator and online videochat software. This methodology was accepted by the participants and judged equivalent to conventional onsite surgical training seminars. Additionally, trainees who participated repeatedly in our sessions showed more satisfactory performance than their initial participation, indicating that our remote training could successfully inspire a part of the participants to achieve significant performance improvement. The results of this study have important implications on surgical education during the COVID-19 pandemic (Figure 5).

\section{Conflict of Interest Statement}

Delivery of simulators and instruments to participants of the remote sessions was consigned to EBM Corporation by the Japanese Society for Cardiovascular Surgery. Ethicon Inc, Johnson \& Johnson provided Japanese Society for Cardiovascular Surgery with Prolene sutures for the young surgeons' training without compensation. All other authors reported no conflicts of interest.

The Journal policy requires editors and reviewers to disclose conflicts of interest and to decline handling or reviewing manuscripts for which they may have a conflict of interest. The editors and reviewers of this article have no conflicts of interest.
The authors thank Hitoshi Yokoyama, MD, PhD, president, Japanese Society for Cardiovascular Surgery (JSCVS), and Hiroshi Yamamoto, MD, PhD, exclusive director of JSCVS U-40, for their support of this project. The authors also thank Yosuke Ishii, MD, $\mathrm{PhD}$, professor and chairman of cardiovascular surgery, Nippon Medical School, for his assistance with institutional review board approval. The authors give special thanks to Young Kwang Park, $\mathrm{PhD}$, EBM Corporation, for his support in developing the simulators and instruments. The authors also thank the JSCVS U-40 secretariat, committee members, and all the participants for their assistance with this project.

\section{References}

1. Higgins M, Madan CR, Patel R. Deliberate practice in simulation-based surgical skills training: a scoping review. J Surg Educ. 2021;78:1328-39.

2. Fann JI, Calhoon JH, Carpenter AJ, Merrill WH, Brown JW, Poston RS, et al. Simulation in coronary artery anastomosis early in cardiothoracic surgical residency training: the Boot Camp experience. J Thorac Cardiovasc Surg. 2010; 139:1275-81.

3. Reznick RK, MacRae H. Teaching surgical skills—changes in the wind. N Engl J Med. 2006;355:2664-9.

4. Fann JI, Caffarelli AD, Georgette G, Howard SK, Gaba DM, Youngblood P, et al. Improvement in coronary anastomosis with cardiac surgery simulation. $J$ Thorac Cardiovasc Surg. 2008;136:1486-91.

5. Hashimoto K. The past, present and future of the Japanese Board of Cardiovascular Surgery. Kyobu Geka. 2017;70:41-5.

6. Watanabe S, Kitagawa T, Tachibana K, Kurosawa H, Chiba K, Ito J, et al. Novel quantitative and objective structured assessment of technical skill for slip knotting. Gen Thorac Cardiovasc Surg. 2020;68:557-64. 
7. Chick RC, Clifton GT, Peace KM, Propper BW, Hale DF, Alseidi AA, et al. Using technology to maintain the education of residents during the COVID-19 pandemic. J Surg Educ. 2020;77:729-32.

8. Reznick R, Regehr G, MacRae H, Martin J, McCulloch W. Testing technical skill via an innovative "bench station" examination. Am J Surg. 1997;173:226-30.

9. Malas T, Al-Atassi T, Brandys T, Naik V, Lapierre H, Lam BK. Impact of visualization on simulation training for vascular anastomosis. J Thorac Cardiovasc Surg. 2018;155:1686-93.e1685.

10. Kanda Y. Investigation of the freely available easy-to-use software 'EZR' for medical statistics. Bone Marrow Transplant. 2013;48:452-8.

11. Park Y, Mita Y, Oki E, Kanemitsu N, Shiraishi Y, Ishii Y, et al. Quantitative evaluation for anastomotic technique of coronary artery bypass grafting by using invitro mock circulatory system. Annu Int Conf IEEE Eng Med Biol Soc. 2007; 2007:2705-8.

12. Ito J, Shimamoto T, Sakaguchi G, Komiya T. Impact of novel off-pump coronary artery bypass simulator on the surgical training. Gen Thorac Cardiovasc Surg. 2013;61:270-3.

13. Tsukui H, Shinke M, Park YK, Yamazaki K. Longer coronary anastomosis provides lower energy loss in coronary artery bypass grafting. Heart Vessels. 2017; 32:83-9.

14. Wu S, Ling Y, Zhao H. Experience with porcine beating heart simulator for coronary artery bypass surgery residency training. J Thorac Cardiovasc Surg. 2021; 161:1878-85.
15. Iki Y, Ito T, Kudo K, Noda M, Kanehira M, Sueta T, et al. Animal ethics and welfare education in wet-lab training can foster residents' ethical values toward life. Exp Anim. 2017;66:313-20.

16. Anastakis D, Wanzel K, Brown M, McIlroy J, Hamstra S, Ali J, et al. Evaluating the effectiveness of a 2-year curriculum in a surgical skills center. Am J Surg. 2003; 185:378-85.

17. Olive JK, Luc JGY, Cerqueira RJ, Eulert-Grehn JJ, Han JJ, Phan K, et al. The cardiothoracic surgery trainee experience during the coronavirus disease 2019 (COVID-19) pandemic: global insights and opportunities for ongoing engagement. J Thorac Cardiovasc Surg. 2020;161:178-83.

18. Coyan GN, Aranda-Michel E, Kilic A, Luketich JD, Okusanya O, Chu D, et al The impact of COVID-19 on thoracic surgery residency programs in the US: a program director survey. J Card Surg. 2020;35:3443-8.

19. Ramphal PS, Coore DN, Craven MP, Forbes NF, Newman SM, Coye AA, et al. A high fidelity tissue-based cardiac surgical simulator. Eur J Cardiothorac Surg. 2005;27:910-6.

Key Words: simulation-based training, remote surgical education, off-the-job training, coronary artery bypass grafting, objective structured assessment of technical skills, COVID-19 